\title{
Heat (Mass) Transfer in a Rotating Two-Pass Square Channel - Part II: Local Transfer Coefficient, Smooth Channel
}

\author{
R.T. KUKREJA ${ }^{\mathrm{a}}$, C.W. PARK ${ }^{\mathrm{b}}$ and S.C. LAU ${ }^{\mathrm{b}, *}$ \\ ${ }^{a}$ Lynntech, Inc., College Station, TX 77841, USA; ${ }^{\mathrm{b}}$ Department of Mechanical Engineering, Texas A\&M University, \\ College Station, TX 77843-3123, USA
}

(Received 21 May 1997; In final form 19 June 1997)

\begin{abstract}
Naphthalene sublimation technique and the heat/mass transfer analogy are used to determine the detailed local heat/mass transfer distributions on the leading and trailing walls of a twopass square channel with smooth walls that rotates about a perpendicular axis. Since the variation of density is small in the flow through the channel, buoyancy effect is negligible. Results show that, in both the stationary and rotating channel cases, very large spanwise variations of the mass transfer exist in the turn and in the region immediately downstream of the turn in the second straight pass. In the first straight pass, the rotation-induced Coriolis forces reduce the mass transfer on the leading wall and increase the mass transfer on the trailing wall. In the turn, rotation significantly increases the mass transfer on the leading wall, especially in the upstream half of the turn. Rotation also increases the mass transfer on the trailing wall, more in the downstream half of the turn than in the upstream half of the turn. Immediately downstream of the turn, rotation causes the mass transfer to be much higher on the trailing wall near the downstream corner of the tip of the inner wall than on the opposite leading wall. The mass transfer in the second pass is higher on the leading wall than on the trailing wall. A slower flow causes higher mass transfer enhancement in the turn on both the leading and trailing walls.
\end{abstract}

Keywords: Heat and mass transfer, Rotating two-pass channel, Naphthalene sublimation

\section{INTRODUCTION}

The blades in advanced gas turbine engines must withstand intense heat because they are exposed to hot gases at very high temperatures. To keep the blade temperatures below critical levels, air is circulated from the compressors through internal multipass or serpentine shaped cooling channels. Since rotation induces Coriolis and buoyancy forces, and a sharp turn causes secondary flows, the flow patterns in these channels are very different from those in stationary straight channels. Coriolis forces push the flows toward the trailing walls for radially outward flows, and toward the leading

*Corresponding author. Tel.: (409) 845-0171. Fax: (409) 862-2418. E-mail: slau @)mengr.tamu.edu. 
walls for radially inward flows. The temperature differences between the flows and the channel walls cause cross-streamwise variations of buoyancy forces, which induce secondary flows along the radial direction. At the sharp turns, the coolant flows separate at the tips of the inner walls and impinge on the outer walls at the turns. The interactions between the forces in the flows due to rotation and those due to the sharp turns result in highly complex flow patterns and large variations of the local heat transfer on all the walls throughout these turbine blade cooling channels.

A survey of the open literature reveals that extensive heat transfer results are available for straight smooth channels, rotating about perpendicular axes. Mori and Nakayama (1968) and Mori et al. (1971) examined laminar and turbulent heat transfer in rotating pipes. Morris and Ayhan (1979) observed the effect of buoyancy force on heat transfer in a rotating pipe. Clifford et al. (1984) conducted experiments with a triangular channel and found that overall heat transfer was enhanced by rotation-induced Coriolis forces. Harasgama and Morris (1988) presented heat transfer results for rotating circular, rectangular, and triangular channels, and showed that rotation increased overall heat transfer. Han and Zhang (1992) and Han et al. (1994) found that uneven wall temperature and heating condition affected the heat transfer in a rotating smooth square channel with radially outward flow. Soong et al. (1991) and Kuo and Hwang (1996) compared heat transfer rates in rotating smooth rectangular ducts of different aspect ratios for both radially inward and outward flows, and demonstrated that Coriolis force had a larger effect on the heat transfer in a square duct than on that in a rectangular duct.

Extensive heat transfer experimental results for rotating serpentine channels with smooth walls were also reported by many researchers. Hajek et al. (1991) and Wagner et al. (1991a,b) showed that rotation increased the regional heat transfer on the smooth pressure surface or trailing wall of a square channel up to 3.5 times that for a corresponding fully developed flow through a stationary, smooth tube. On the other hand, the leading wall experienced regional heat transfer decrease of up to $60 \%$ of the stationary tube value.

Yang et al. (1992) and Mochizuki et al. (1994) also examined the effect of Coriolis and buoyancy forces on the heat transfer in smooth, rotating serpentine channels. Han et al. (1993) studied the effect of uneven wall heating condition on the heat transfer on the walls of a two-pass, smooth, square channel. Dutta et al. (1994) reported the effect of channel orientation on the heat transfer in a rotating two-pass triangular channel with smooth walls. Hwang and Kuo (1994) conducted experiments with a rotating smooth three-pass channel, and reported that the heat transfer enhancement on the trailing wall of the first pass with outward flow was more noticeable than that on the walls of the other two passes.

Tse et al. (1994), Tse and McGrath (1995), and McGrath and Tse (1995) measured the local velocity distributions in a rotating serpentine channel with smooth walls, and compared their experimental results with distributions that were predicted numerically by solving the relevant governing conservation equations with a Navier-Stokes code by Rhie (1986). Other recent numerical studies on turbulent flow and heat transfer in rotating smooth channels include Prakash and Zerkle (1992) and Dutta et al. (1994).

In this investigation, the naphthalene sublimation technique and the heat/mass transfer analogy are used to determine the detailed local heat/mass transfer distributions on the walls of a two-pass square channel with smooth walls that rotates about a perpendicular axis. Presently, most experimental heat transfer results in the open literature are regionally averaged heat transfer results. Attention is focused on the mass transfer distributions on the two principal walls, that is, the leading and trailing walls, of the test channel. The main objective of this study is to make available detailed local experimental heat/mass transfer data to enable better understanding of the effects of rotation and a sharp turn on the local heat/mass transfer distribution in a rotating two-pass square smooth channel, and to 
help improve the design of serpentine cooling channels in the blades of high-performance gas turbine engines.

During the naphthalene sublimation experiments, the walls of the test channel and the air that flows through the test channel were both at room temperature. There was no density variation in the test channel due to temperature variation in the flow field. Furthermore, since the naphthalene partial pressure at the test channel walls in all the experiments in this study was very small, the naphthalene vapor concentration at the test channel walls was very small. The maximum density variation in the naphthalene vapor-air mixture that flows through the test channel (the difference between the mixture density at the channel walls and the inlet air density divided by the inlet air density) was found to be $5 \times 10^{-4}$. Thus, buoyancy effect in actual turbine blade cooling channels, which the test channel modeled, was not simulated, and the results to be presented will illustrate only the effects of Coriolis forces and turn-induced secondary flows on the local heat/mass transfer distribution.

\section{TEST APPARATUS AND PROCEDURE}

The main component of the test apparatus was the test section that was a two-pass square channel constructed entirely of aluminum. Both of the two straight segments of the test section and the tip clearance at the sharp $180^{\circ}$ turn had a flow cross section of $1.59 \mathrm{~cm} \times 1.59 \mathrm{~cm}$. Each straight segment had a length of $11.11 \mathrm{~cm}$, which was equivalent to seven times the channel hydraulic diameter. The test section had seven separate walls: two principal walls, two inner side walls, two outer side walls, and an end wall. A $1.59 \mathrm{~cm}$ wide shallow groove was machined off one surface of each wall and the groove was then filled with naphthalene during a casting process. Figure 1 shows a photograph of the naphthalene-coated surfaces of the test section walls. Once these walls were assembled, the interior surfaces of the test section were all mass transfer

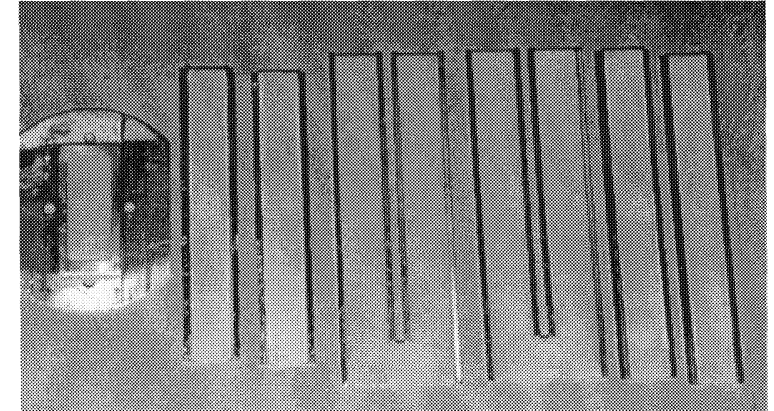

FIGURE 1 Naphthalene-coated test section walls.

active, and the two inner walls had a total thickness of $0.79 \mathrm{~cm}$, which was one-half of the channel hydraulic diameter. Note that the walls were designed and constructed such that none of the rims of the walls were exposed to the flowing air during an experiment.

The seven walls of the test section were assembled inside a rectangular aluminum housing that had two parallel square channels separated by a $0.79 \mathrm{~cm}$ thick wall. Once the seven individual walls were secure inside this housing, the assembly consisted of an entrance channel, the two-pass test channel, and an exit channel. The entrance and exit channels had the same cross section as the test section and had lengths of 10 and 20 hydraulic diameters, respectively. The end of this assembly with the outlet of the exit was welded to a short horizontal aluminum tube that was affixed to the vertical steel shaft of a rotating test rig. The mean rotating radius, that is, the distance from the rotating axis to the middle of the test section, was 30 times the hydraulic diameter of the test section. Figure 2 shows the rotating test rig with the rotating shaft supported by two bearings in a heavy steel cage. A five horsepower electric motor drove the vertical shaft using two pulleys and a belt. The aforementioned short horizontal tube supported the entrance/test/exit channel assembly at one end and an aluminum tube with a counterweight at the other end.

Not shown in Fig. 2 is an aluminum containment tube with the same diameter as the tube with the counterweight that enclosed the entire entrance/ test/exit channel assembly. Also not shown are 


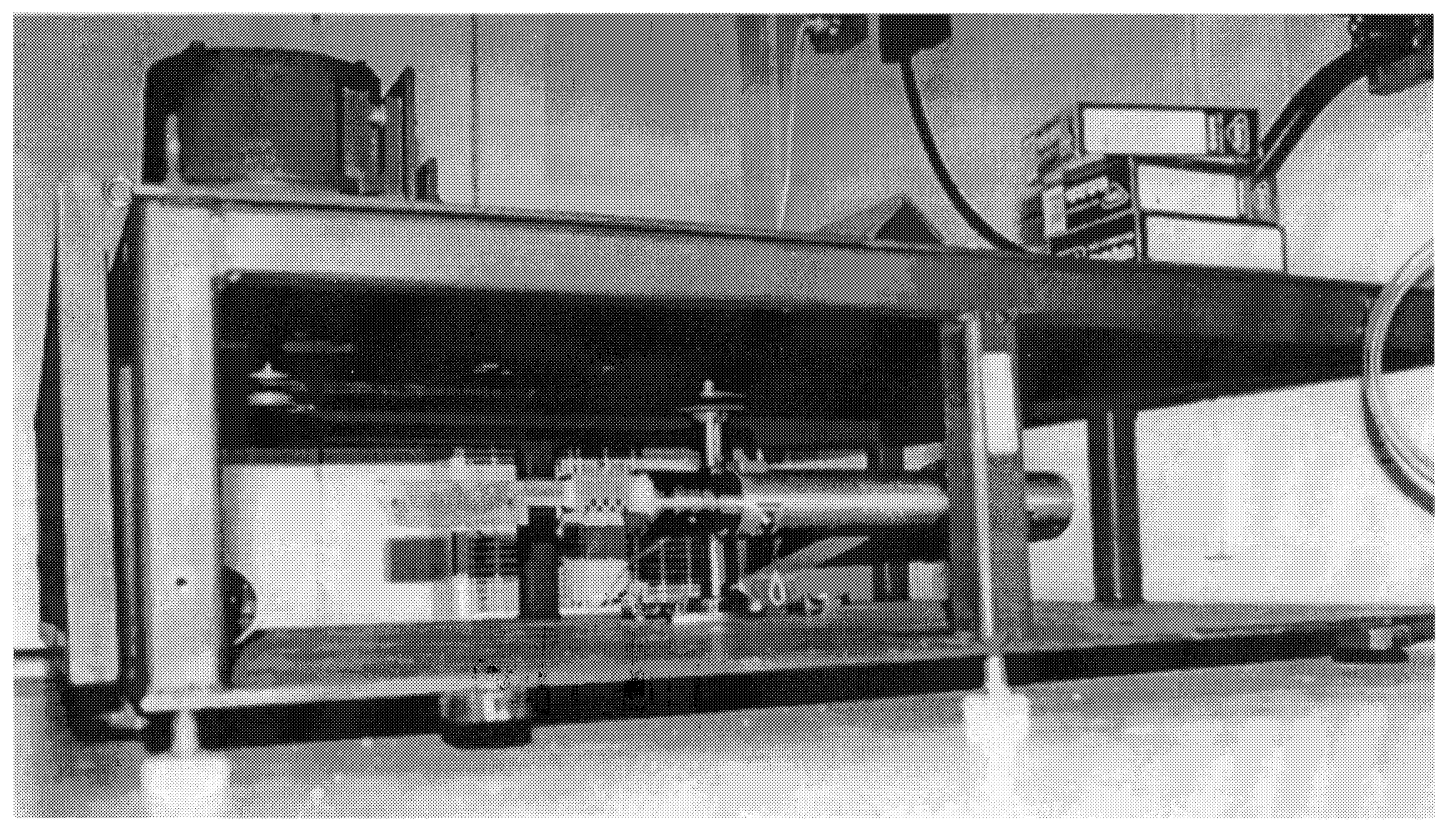

FIGURE 2 Rotating test rig.

removable heavy steel meshes that fenced the vertical faces of the steel gage. The meshes were reinforced on the inside with steel angles and thick plywood boards. It should be pointed out that the seven separate walls of the test section and the containment tube were designed such that they might be installed very quickly to minimize mass transfer from the test section walls before and after air was allowed to flow through the rotating test section steadily.

Air was drawn through bleed holes on the containment tube and then the inlet/test/exit section assembly with a centrifugal blower. The air then flowed through the hollow rotating shaft, a rotating union, a calibrated orifice flow meter for flow rate measurement, and a gate valve for flow rate control, before it was ducted to an exhaust hood.

To obtain the distributions of the local mass transfer coefficient on the two principal walls of the test section, the surface elevations at a predetermined grid of points on each of the two naphthalene-coated walls were measured and recorded at the beginning and the end of each test run. Figure 3 shows the grid of points on each wall

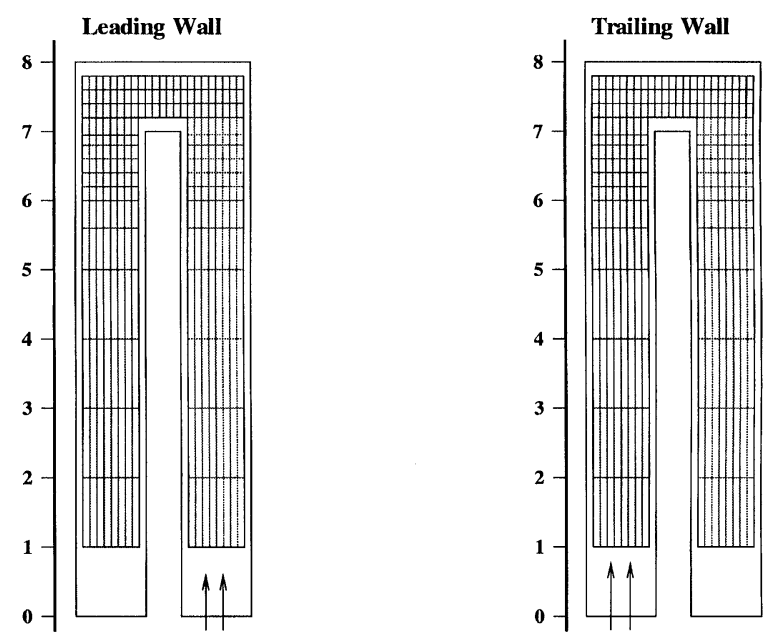

FIGURE 3 Grid of local elevation measurement points.

for local elevation measurement. The elevations were measured with a computer-controlled system that included an electronic depth gage with a levertype sensor, an electronic amplifier, and a resolution of $0.00025 \mathrm{~mm}$, and a coordinate table with stepper motors. 
An electronic balance with a resolution of $0.01 \mathrm{mg}$ (or $0.1 \mathrm{mg}$ over a larger range) was used to determine the weights of the seven walls. A Utube manometer measured the pressures at the orifice flow meter and thermocouples measured the air temperatures at the test section inlet and at the orifice flow meter. An electronic tachometer was used to measure the rotational speed.

A test run was initiated by weighing all the walls and by obtaining the initial elevations at the grid of points on each of the two principal walls. The test section and the containment tube were then quickly assembled. After the motor was switched on to rotate the test section at the desired angular velocity, air was drawn through the test section with the blower. A test run typically lasted one to two hours. During the run, the air flow rate and the air temperatures were monitored and recorded periodically. At the completion of the run, each wall was weighed and the elevations at the same grid of points were measured again.

Separate experiments were carried out to determine the correction to the local mass transfer that was necessary due to convection losses during motor and blower start up and shut down, and while the local and overall measurements were conducted.

\section{DATA REDUCTION}

The Reynolds number and the rotation number are defined, respectively, as

$$
R e=\frac{\dot{m}}{\mu D}
$$

and

$$
R o=\frac{\Omega D}{U},
$$

where $\Omega$ is the rotational speed and $U$ is the average velocity of the air flow through the test channel. The rotation number may be considered as the strength of the Coriolis force relative to that of the inertia force.
The local mass transfer coefficient is evaluated as

$$
h_{m}=\frac{\dot{m}^{\prime \prime}}{\rho_{\mathrm{w}}-\rho_{\mathrm{b}}},
$$

where $\dot{m}^{\prime \prime}$ is the rate of mass transfer per unit surface area, $\rho_{\mathrm{w}}$ is the naphthalene vapor density at the wall, which is uniform throughout the channel, and $\rho_{\mathrm{b}}$ is the bulk naphthalene vapor density in the air stream.

The mass flux at each measurement point is evaluated from the density of solid naphthalene, $\rho_{\mathrm{s}}$, and the change of elevation during a test run, $\Delta z$, after applying the correction due to mass losses at the beginning and the end of the test run:

$$
\dot{m}^{\prime \prime}=\frac{\rho_{\mathrm{s}} \Delta z}{\Delta t},
$$

where $\Delta t$ is the duration of the test run. The naphthalene vapor density at the wall, $\rho_{\mathrm{w}}$, in Eq. (3) is calculated using the ideal gas law along with the vapor pressure-temperature relation for naphthalene according to Ambrose et al. (1975):

$T\left(\log _{10} p_{\mathrm{w}}\right)=\frac{1}{2} a_{0}+\sum a_{s} E_{s}(x), \quad s=1,2$, and 3,

where $a_{0}=301.6247, a_{1}=791.4937, a_{2}=-8.2536$, and $a_{3}=0.4043 ; \quad x=(2 T-574) / 114 ; \quad E_{1}(x)=x$, $E_{2}(x)=2 x^{2}$, and $E_{3}(x)=4 x^{3}-3 x$. In Eq. (5), $p_{\mathrm{w}}$ is in pascals and $T$ is in degrees Kelvin.

The bulk density of naphthalene in the air stream, $\rho_{\mathrm{b}}$, at any streamwise location is calculated as

$$
\rho_{\mathrm{b}}=\frac{C_{m}}{\dot{Q}},
$$

where the cumulative mass, $C_{m}$, is the rate of mass at which naphthalene enters the air stream from the portion of the test section walls upstream of the streamwise location, and $\dot{Q}$ is the volumetric air flow rate. The weights of the test section walls at the beginning and at the end of a test run are used to determine the bulk densities at the turn and at 
the test section exit. Since the bulk density at the inlet of the test section is zero, the bulk density at any streamwise location is determined by linearly interpolating the bulk density values at the inlet, the sharp turn, and the outlet of the test section. The bulk naphthalene vapor density at the test channel exit is found to be between $18 \%$ and $25 \%$ of the naphthalene vapor density at the wall.

The Sherwood number is

$$
S h=\frac{h_{m} D}{\Lambda} .
$$

The diffusion coefficient for naphthalene vapor in air, $\Lambda$, is calculated by

$$
\Lambda=0.0681\left(\frac{T}{298.16}\right)^{1.93}\left(\frac{1.013 \times 10^{5}}{p_{\mathrm{atm}}}\right),
$$

where $\Lambda$ is in $\mathrm{cm}^{2} / \mathrm{s}, p_{\text {atm }}$ is in pascals, and $T$ is in degrees Kelvin. Equation (8) gives the Schmidt number of naphthalene vapor in air of about 2.28. The Sherwood number is normalized by the Sherwood number for a corresponding fully developed flow in a stationary smooth tube, which is determined with the Dittus-Boelter equation:

$$
S h_{0}=0.023 R e^{0.8} S c^{0.4}
$$

The heat/mass transfer analogy relates the Nusselt number to the Sherwood number as follows:

$$
N u=\left(\frac{P r}{S c}\right)^{0.4} \cdot S h
$$

or

$$
N u / N u_{0}=S h / S h_{0} .
$$

It is found that a $0.5^{\circ} \mathrm{C}$ deviation in the surface temperature changes the naphthalene vapor density at the surface by as much as 5\%. The mass flow rate of air, the local naphthalene mass flux, the naphthalene vapor density at the wall (relative to $\rho_{\mathrm{w}}-\rho_{\mathrm{b}}$ ), and the bulk naphthalene vapor density in the air stream (relative to $\rho_{\mathrm{w}}-\rho_{\mathrm{b}}$ ), have uncertainties of $4.3 \%, 3.1 \%, 7.5 \%$, and $6.7 \%$, respectively. Using the method described in Coleman and Steele (1989), the maximum uncertainties for the Reynolds number and the Sherwood number are estimated to be $4.8 \%$ and $10.8 \%$.

\section{RESULTS}

Naphthalene sublimation experiments were conducted with Reynolds numbers between 5,500 and 14,500 , and rotation number up to 0.24 . The Reynolds number and rotation number ranges correspond to mean flow velocities between 5.3 and $14.0 \mathrm{~m} / \mathrm{s}$, and rotational speeds up to $770 \mathrm{rpm}$. The local mass transfer distributions on the leading and trailing walls of the two-pass test channel with smooth walls are presented as contours of the normalized Sherwood number in this section. Table I summarizes the conditions of the various test cases.

\section{Stationary Channel}

Figures 4(a)-(c) present the local mass transfer distributions on the leading and trailing walls of the test channel in the three cases of no rotation: Cases A, B, and C, respectively. The corresponding Reynolds numbers are 5,500, 10,000, and 14,500. Without rotation, the flow through the two-pass channel should be symmetrical with respect to the midplane between the leading and trailing walls. The figures show that the mass transfer distributions

TABLE I Conditions of test cases

\begin{tabular}{lccccccccc}
\hline Case & $\mathrm{A}$ & $\mathrm{B}$ & $\mathrm{C}$ & $\mathrm{D}$ & $\mathrm{E}$ & $\mathrm{F}$ & $\mathrm{G}$ & $\mathrm{H}$ & $\mathrm{I}$ \\
\hline$R o$ & 0.0 & 0.0 & 0.0 & 0.05 & 0.09 & 0.09 & 0.09 & 0.16 & 0.24 \\
$R e$ & 5,500 & 10,000 & 14,500 & 10,000 & 5,500 & 10,000 & 14,500 & 5,500 & 5,500 \\
\hline
\end{tabular}




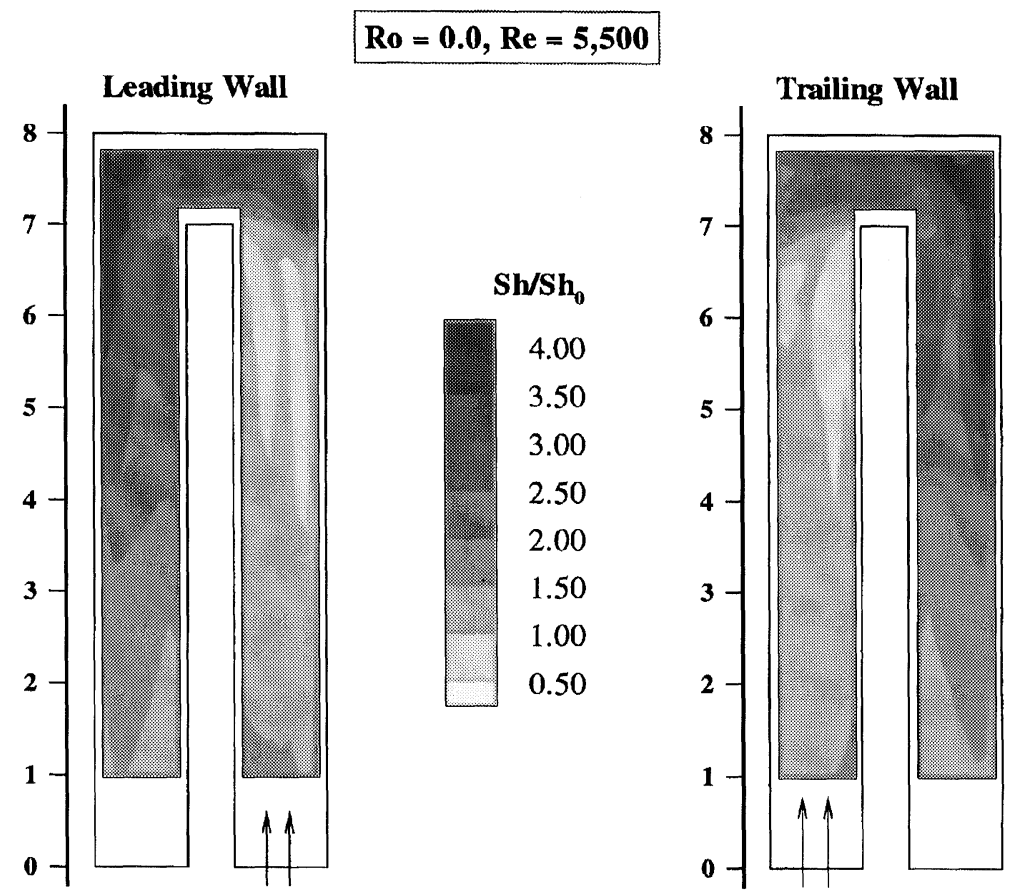

FIGURE 4(a) Local mass transfer distributions on leading and trailing walls, Case A, $R o=0.0$ and $R e=5,500$.

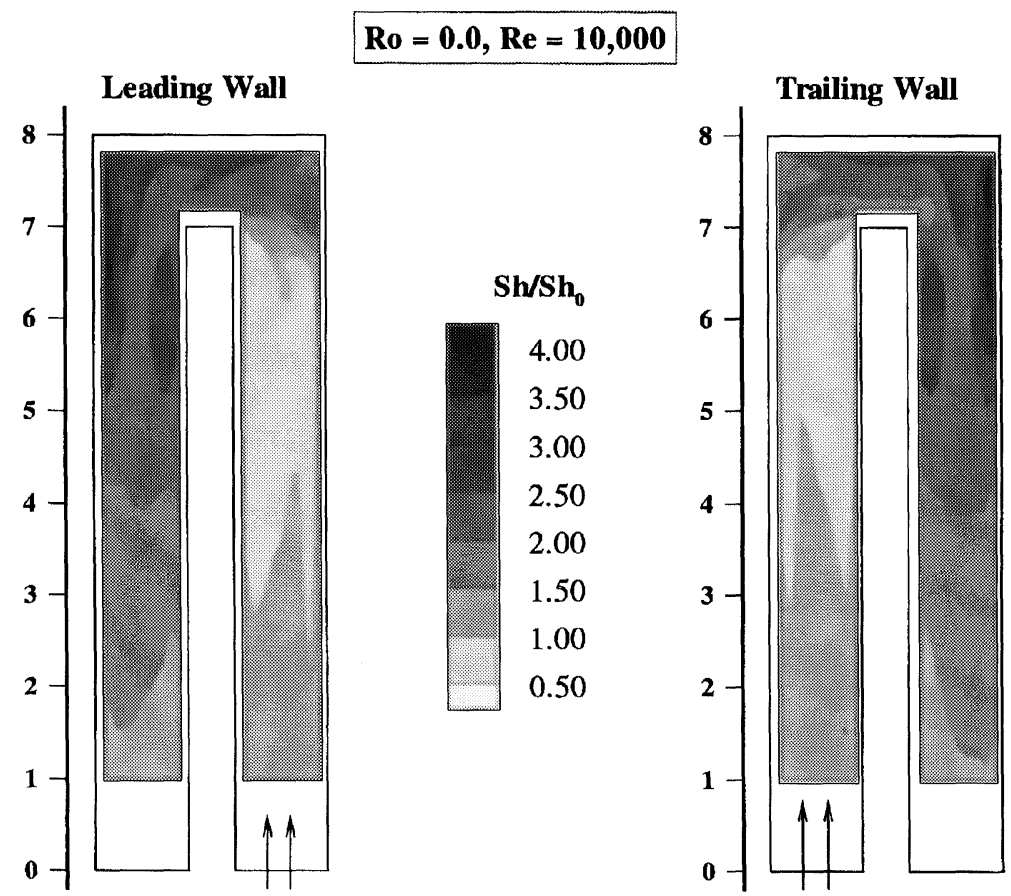

FIGURE 4(b) Local mass transfer distributions on leading and trailing walls, Case $\mathrm{B}, R o=0.0$ and $R e=10,000$. 


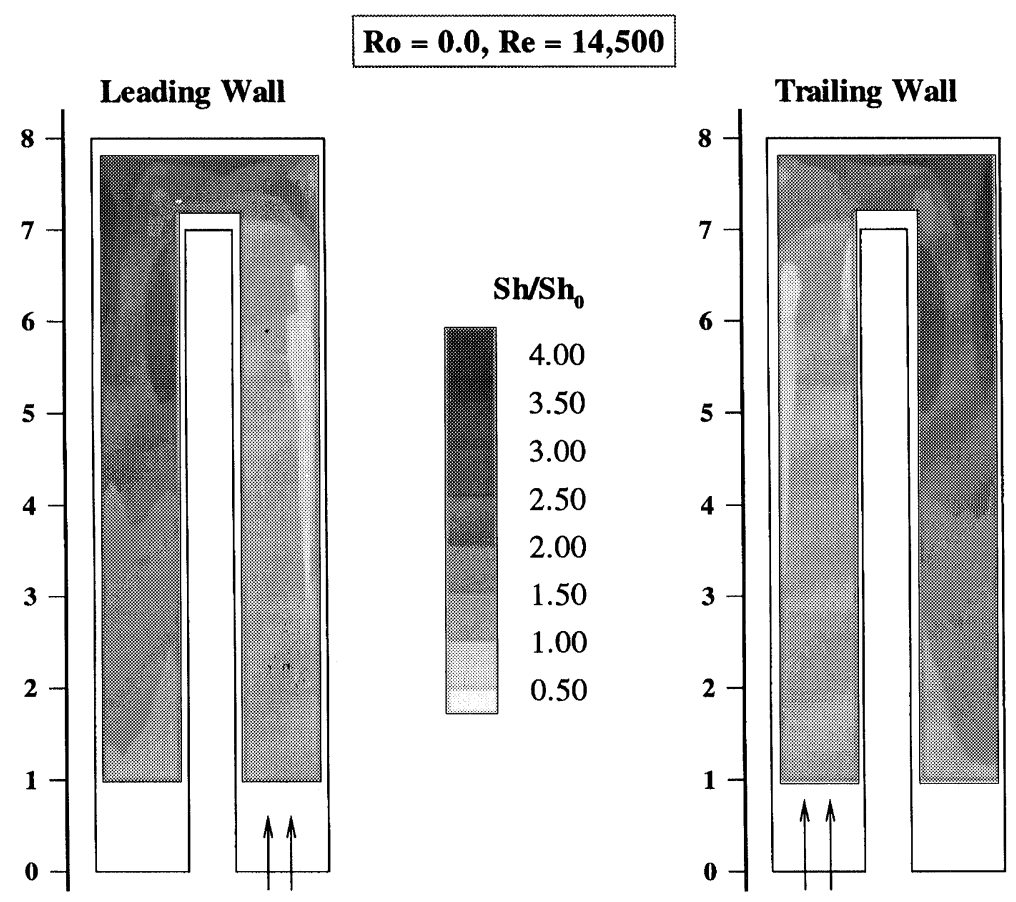

FIGURE 4(c) Local mass transfer distributions on leading and trailing walls, Case C, $R o=0.0$ and $R e=14,500$.

on the two walls are very similar. Along the first straight pass, the Sherwood number ratio decreases monotonically on both walls with distance from the channel entrance, as the flow develops. The value of $S h / S h_{0}$ reaches about 1.0 upstream of the turn. Thus, both the flow field and the naphthalene concentration field may be considered fully developed entering the turn.

In the turn, a portion of the flow impinges on the end wall and is deflected toward the leading and trailing walls, resulting in high mass transfer along the outer edges of the walls at the turn. The value of $S h / S h_{0}$ near the end wall is between 2.8 and 3.5 in the three distributions. The presence of a region with relatively slow recirculating flow is evident on each wall near the upstream outer corner of the turn. As much of the flow turns away from this outer corner, $S h / S h_{0}$ has values between about 1.5 and 2.5, as shown in Figs. 4(a)-(c).

The secondary flows that are induced by centrifugal forces at the turn cause vigorous turbulent mixing, resulting in high $S h / S h_{0}$ values throughout the turn region. The value of $S h / S h_{0}$ in the turn is generally higher near the end wall and lower at the tip of the inner wall, except near the upstream outer corner. Also, the values of $S h / S h_{0}$ in the turn and downstream of the turn are much higher in Case A $(R e=5,500)$ than in Cases B and C $(R e=10,000$ and 14,500 , respectively), indicating higher mass transfer enhancement in the turn and downstream of the turn when the flow rate is lower.

As the flow exits the sharp turn and enters the second pass, the flow impinges on the outer side wall and is deflected toward the two principal walls, causing very high mass transfer along the outer edges of the two walls. The mass transfer is also quite high near the inner wall at the entrance of the second straight pass, as some of the flow that separates at the tip of the inner side wall reattaches on the downstream side of the inner wall and spreads toward the leading and trailing walls.

Along the second straight pass, $S h / S h_{0}$ decreases monotonically, as the flow redevelops. The increased turbulence due to the turn results in 
significantly higher mass transfer on the principal walls in the second pass than in the first pass. The $S h / S h_{0}$ value decreases to about 1.4 at its exit, in each of Figs. 4(a)-(c).

The $S h / S h_{0}$ distribution in Fig. 4(b) is very similar to the $N u / N u_{0}$ distribution for turbulent flow through a stationary square channel with a sharp turn $(R e=10,000)$ given in Fig. 6 in Ekkad and Han (1995). The heat or mass transfer is high near the end wall and the downstream outer wall. The high heat or mass transfer region near the downstream side of the inner wall that is evident in Fig. 4(b), however, was not observed by Ekkad and Han (1995). The slight difference in the two distributions may be the result of the different shapes of the tips of the inner walls in the two studies.

\section{Effect of Rotation}

Figures 5(a) and (b) show the $S h / S h_{0}$ distributions on the leading and trailing walls in Cases $\mathrm{D}$ and $\mathrm{F}$, with $R e=10,000$ and $R o=0.05$ and 0.09 , respec- tively. Rotation changes the mass transfer distributions on the leading and trailing walls considerably. In the first straight pass, the rotation-induced Coriolis forces push the flow toward the trailing wall. Cross stream secondary flows reduce the mass transfer on the leading wall and increase the mass transfer on the trailing wall. Figure 5(a) shows that the value of $S h / S h_{0}$ on the leading wall decreases to as low as 0.45 along the first pass. Similarly, with $R o=0.09$, the value of $S h / S h_{0}$ on the leading wall is as low as 0.3 in the first pass. A slightly asymmetric inlet flow may have caused the higher leading wall mass transfer near the outer wall than near the inner wall. On the trailing wall, the value of $S h / S h_{0}$ ranges between 1.1 and 1.4, and the mass transfer distributions do not have significant spanwise variations.

Attention is now focused on the turn. Rotation significantly increases the mass transfer on the leading wall in the turn, especially in the upstream half of the turn. The mass transfer on the leading wall is considerably higher in the turn than in the first pass, and there is a rather abrupt increase of

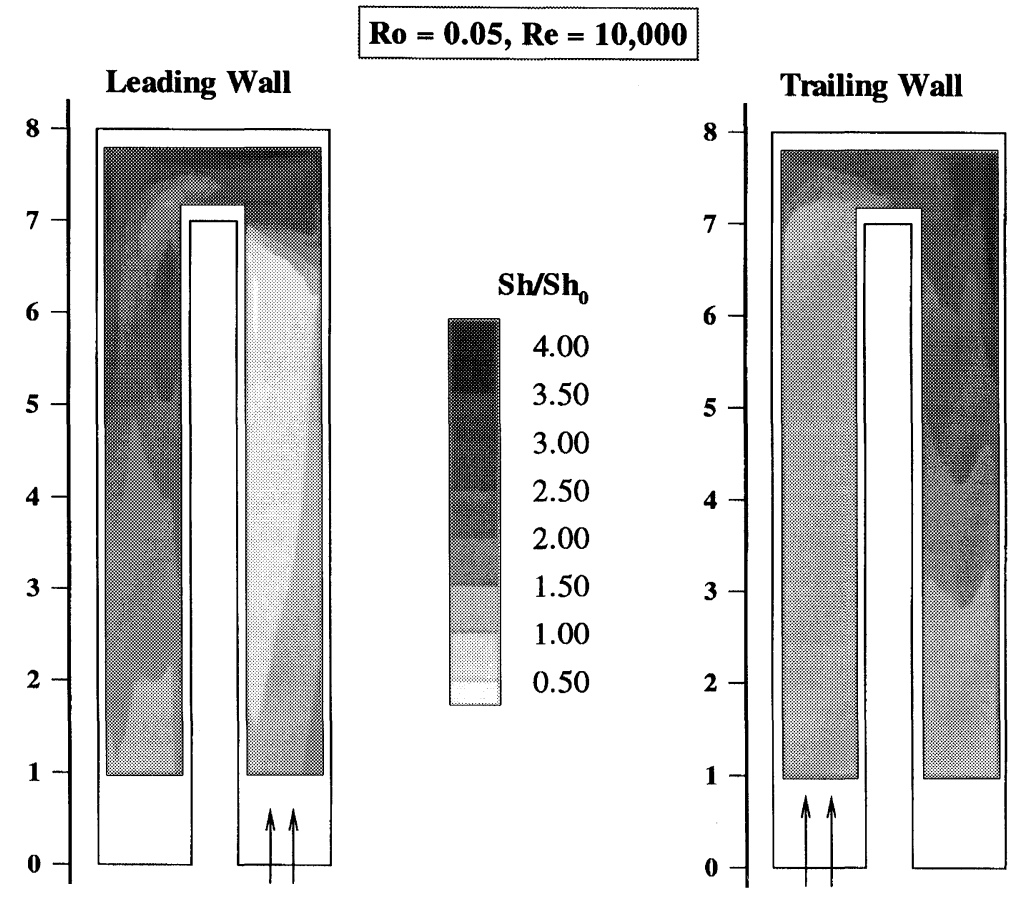

FIGURE 5(a) Local mass transfer distributions on leading and trailing walls, Case D, $R o=0.05$ and $R e=10,000$. 


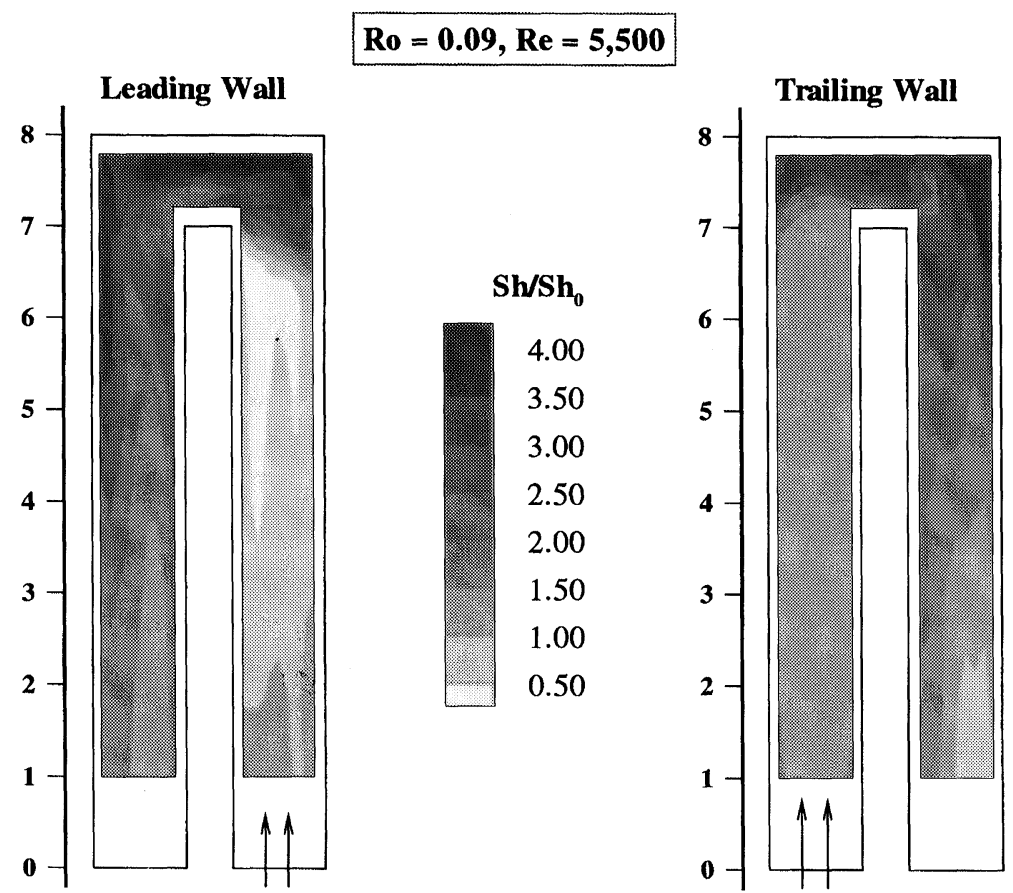

FIGURE 5(b) Local mass transfer distributions on leading and trailing walls, Case F, $R o=0.09$ and $R e=10,000$.

the mass transfer at the turn entrance. The $S h / S h_{0}$ values on the leading wall in the upstream half of the turn are larger than those in the downstream half of the turn. The trend is the opposite of that in the corresponding no-rotation case (Case B). The high mass transfer region near the end wall is shifted toward the upstream corner of the turn, and is much wider, spreading across almost the entire edge of the wall. With rotation, the leading wall mass transfer is lower in the downstream half of the turn than in the upstream half of the turn. A low mass transfer region, with $S h / S h_{0}$ values as low as 1.5 , is evident on the leading wall at the turn exit near the tip of the inner side wall.

Figures 5(a) and (b) show that rotation also increases the mass transfer on the trailing wall, more in the downstream half of the turn than in the upstream half of the turn. The $S h / S h_{0}$ values in the upstream half of the turn are higher than those in the no-rotation case, whereas the $S h / S h_{0}$ values in the downstream half of the turn are about the same as those in the no-rotation case.
In the second pass, while the high mass transfer region along the outer side wall on the leading wall is not affected by rotation, the high mass transfer region along the outer side wall on the trailing wall is shifted upstream toward the second outer corner of the turn. With increasing rotational speed, the local peak in the leading wall mass transfer distribution along the inner wall is reduced and that in the trailing wall mass transfer distribution along the inner wall are moved to a location very close to the second inner corner of the turn.

The mass transfer is generally higher in the second pass than in the first pass on both of the principal walls. The increased turbulence induced by the turn enhances the mass transfer on both walls in the second pass. Since the flow in the second pass is radially inward, Coriolis forces are supposed to increase the mass transfer on the leading wall and reduce that on the trailing wall. However, the interaction between secondary flows that are caused by the turn and Coriolis forces (which are relatively small in these cases of low 
rotational speeds) keeps the mass transfer on the leading wall almost the same as that on the trailing wall, except far downstream of the turn, where the mass transfer is slightly lower on the trailing wall. Along the second pass, as the flow redevelops, the mass transfer on the two walls decreases, with values of $S h / S h_{0}$ drop about 1.2.

Figures 6(a)-(c) present the local mass transfer distributions in Cases $\mathrm{E}, \mathrm{H}$, and $\mathrm{I}$, with rotation numbers of 0.09 and 0.16 , and 0.24 , respectively. The Reynolds numbers in all three cases are 5,500. The distributions are similar qualitatively to those for the two higher Reynolds number cases: Cases D and $F$. They again show that increasing the rotational speed reduces the mass transfer on the leading wall and increases that on the trailing wall, in the first pass. Figure 6(c) demonstrates that increasing the rotation number to 0.24 intensifies the cross stream vortices. Coriolis forces push much of the flow toward the trailing wall, and results in a large difference between the mass transfer on the leading wall and that on the trailing wall in the first pass: with $S h / S h_{0}$ values of less than 0.3 versus values of about 1.6.

With $R o=0.24$, the effect of Coriolis forces on the mass transfer on the leading and trailing walls for the radially inward flow in the second pass becomes evident. In the second pass, the mass transfer is higher on the leading wall than on the trailing wall. The high mass transfer regions on the leading wall along the end wall and the downstream outer side wall have very large $S h / S h_{0}$ values of over 4.0. On the trailing wall, there is a high mass transfer region at the downstream outer corner of the turn. However, the region does not extend as far downstream along the outer side wall as the opposite high mass transfer region on the leading wall.

Figure 6(c) clearly indicate a peak with values exceeding 4.0 on the trailing wall very close to the downstream inner corner of the turn. Also, there is not a local peak in the leading wall $S h / S h_{0}$ distribution along the downstream side of the inner wall. Finally, high rotational speed reduces the leading

\section{$\operatorname{Ro}=0.09, \operatorname{Re}=5,500$}
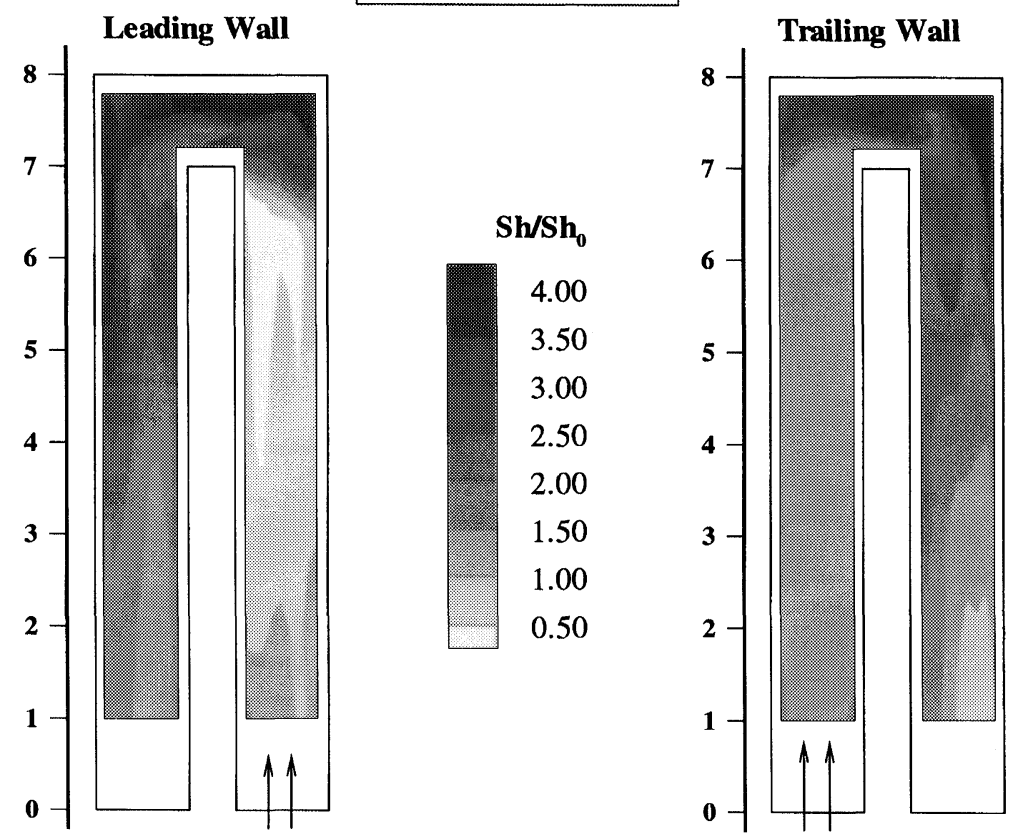

FIGURE 6(a) Local mass transfer distributions on leading and trailing walls, Case E, $R o=0.09$ and $R e=5,500$. 


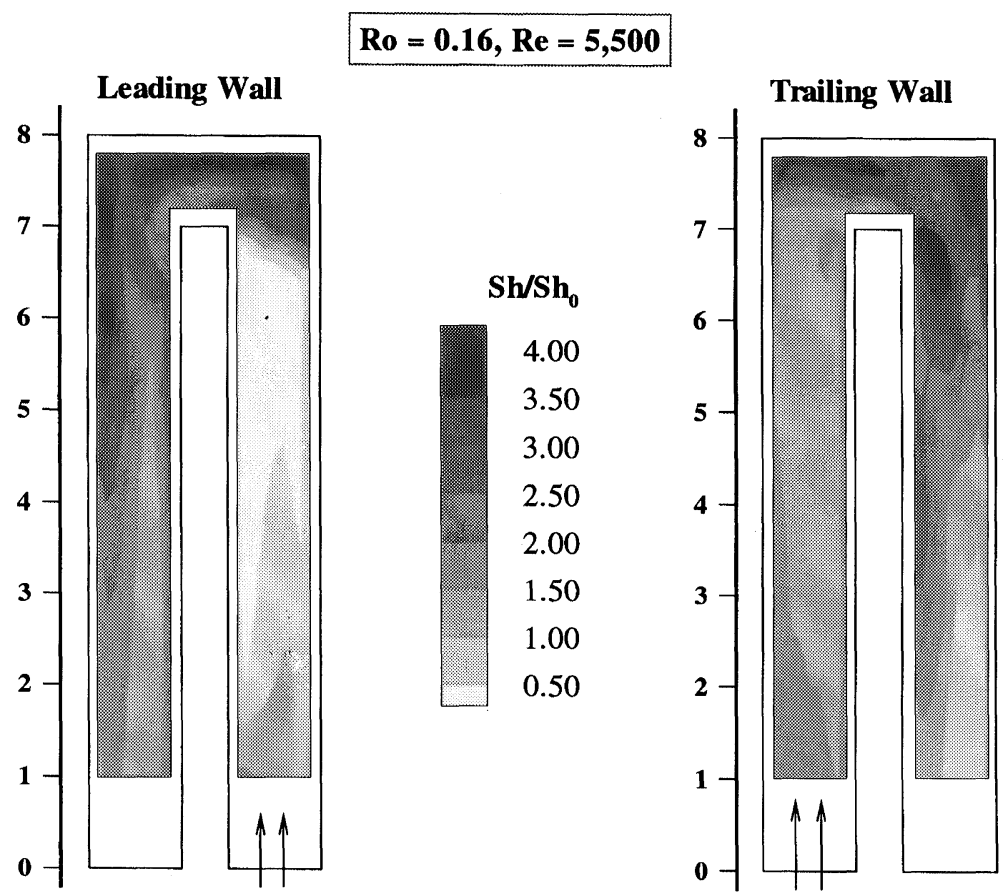

FIGURE 6(b) Local mass transfer distributions on leading and trailing walls, Case $\mathrm{H}, R o=0.16$ and $R e=5,500$.

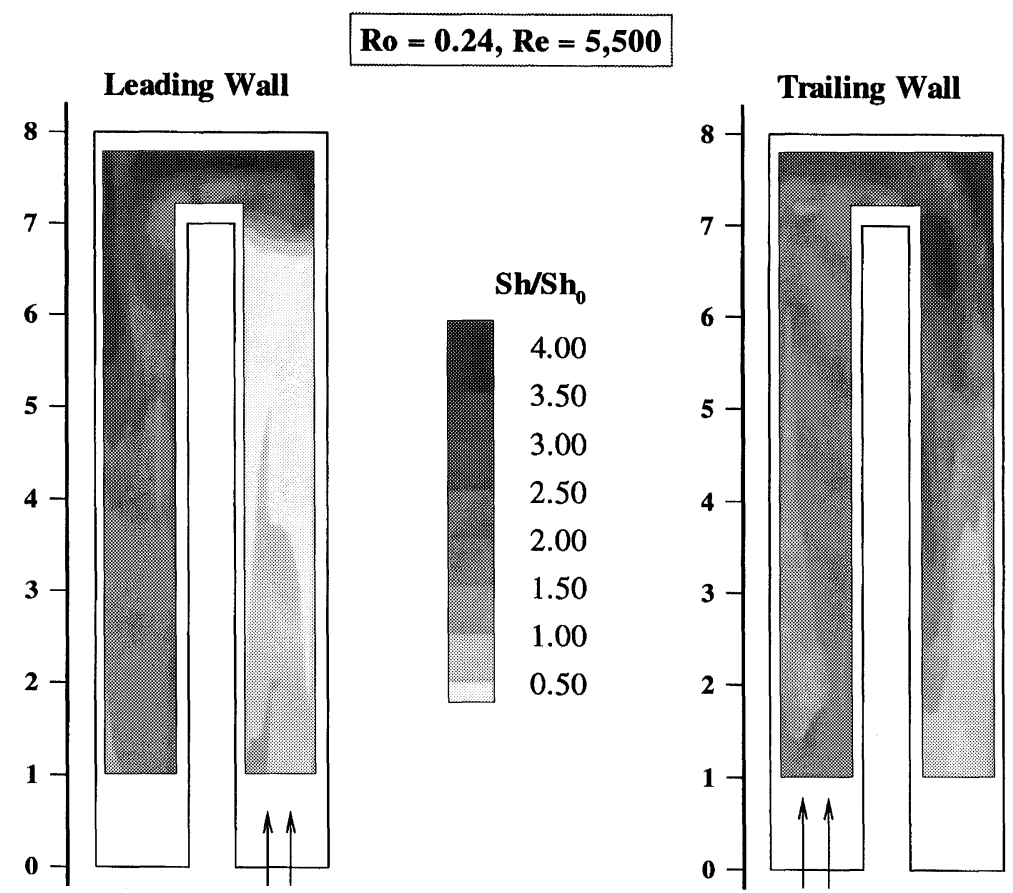

FIGURE 6(c) Local mass transfer distributions on leading and trailing walls, Case I, $R o=0.24$ and $R e=5,500$. 


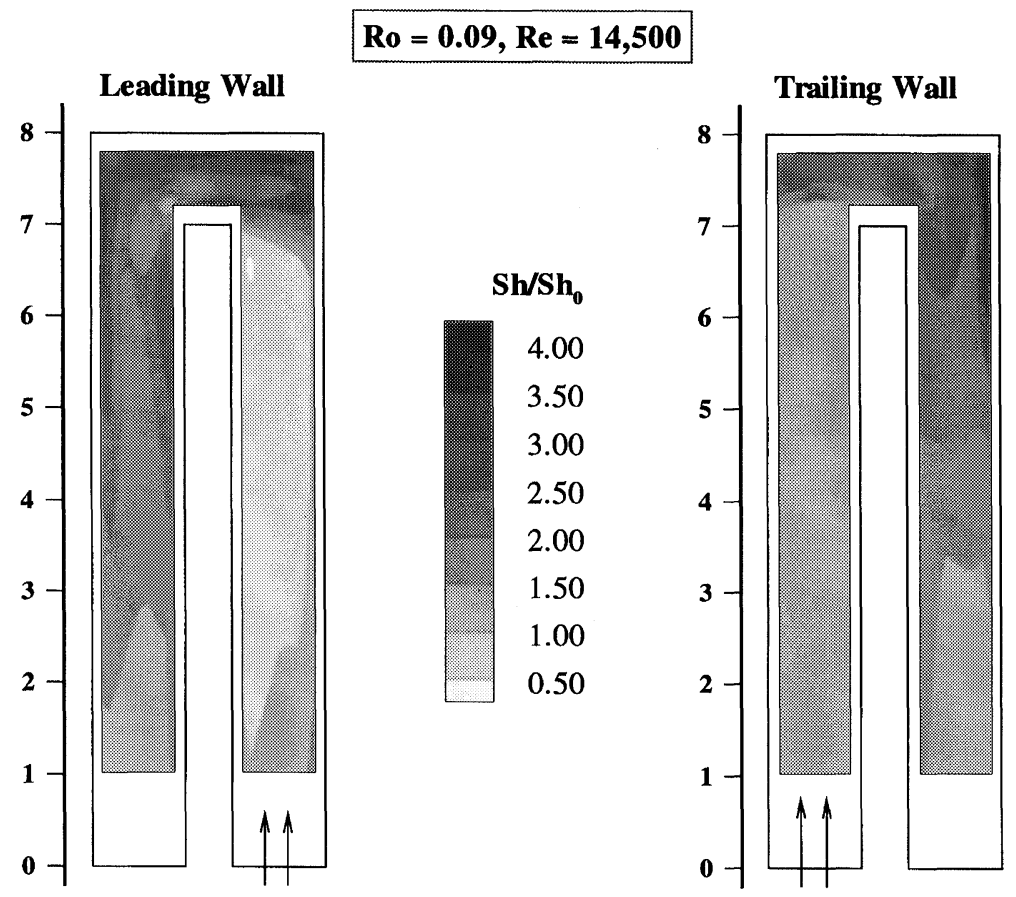

FIGURE 7 Local mass transfer distributions on leading and trailing walls, Case $\mathrm{G}, R o=0.09$ and $R e=14,500$.

wall mass transfer at the tip of the inner wall in the turn.

Figure 7 gives the local mass transfer distributions in Case G, with $R o=0.09$ and $R e=14,500$. Comparing Figs. 5(b), 6(a), and 7 (Cases E, F, and $\mathrm{G})$, it is evident that increasing the Reynolds number from 5,500 to 14,500 does not change the trends of the local distributions on the two walls. Increasing the Reynolds number decreases slightly the difference between the $S h / S h_{0}$ values on the leading wall and those on the trailing wall in the first straight pass. The Reynolds number effect is, however, much more obvious in the turn. A slower flow causes higher mass transfer enhancement in the turn on both the leading and trailing walls.

\section{CONCLUDING REMARKS}

Naphthalene sublimation experiments have been conducted to determine the detailed local mass transfer distributions on the leading and trailing walls of a two-pass square channel with smooth walls that rotates about a perpendicular axis. The following conclusions may be drawn:

1. In both the stationary and rotating channel cases, very large spanwise variations of the mass transfer exist in the turn and in the region immediately downstream of the turn in the second straight pass.

2. In the first straight pass, the rotation-induced Coriolis forces reduce the mass transfer on the leading wall and increase the mass transfer on the trailing wall. There is a larger streamwise mass transfer variation on the leading wall of the first straight pass than on the opposite trailing wall.

3. In the turn, rotation significantly increases the mass transfer on the leading wall, especially in the upstream half of the turn. Rotation also increases the mass transfer on the trailing wall, more in the downstream half of the turn than in the upstream half of the turn. 
4. The mass transfer is higher in the second pass than in the first pass on both of the principal walls due to the increased turbulence at the turn. Immediately downstream of the turn, rotation causes the mass transfer to be much higher on the trailing wall near the downstream corner of the tip of the inner wall than on the opposite leading wall. The mass transfer in the second pass is higher on the leading wall than on the trailing wall.

5. A slower flow causes higher mass transfer enhancement in the turn on both the leading and trailing walls.

\section{NOMENCLATURE}

$C_{m}$ cumulative mass of naphthalene in air stream $[\mathrm{kg} / \mathrm{s}]$

$D \quad$ test channel hydraulic diameter [m]

$h_{m} \quad$ local mass transfer coefficient, $\dot{m}^{\prime \prime} /\left(\rho_{\mathrm{w}}-\rho_{\mathrm{b}}\right)[\mathrm{m} / \mathrm{s}]$

$\dot{m} \quad$ air mass flow rate $[\mathrm{kg} / \mathrm{s}]$

$\dot{m}^{\prime \prime}$ local mass flux on naphthalene surface, $\rho_{\mathrm{s}} \Delta z / \Delta t\left[\mathrm{~kg} /\left(\mathrm{m}^{2} \mathrm{~s}\right)\right]$

$\mathrm{Nu} \quad$ Nusselt number

$N u_{0} \quad$ reference Nusselt number, $0.023 \operatorname{Re}^{0.8} \operatorname{Pr}^{0.4}$

$p_{\text {atm }}$ atmospheric pressure $\left[\mathrm{N} / \mathrm{m}^{2}\right]$

$p_{\mathrm{w}} \quad$ vapor pressure of naphthalene at channel walls $\left[\mathrm{N} / \mathrm{m}^{2}\right]$

Pr Prandtl number

$\dot{Q} \quad$ air volumetric flow rate $\left[\mathrm{m}^{3} / \mathrm{s}\right]$

Re Reynolds number, $\dot{m} /(\mu D)$

$R o$ rotation number, $\Omega D / U$

Sc Schmidt number

$S h \quad$ Sherwood number, $h_{m} D / \Lambda$

$S h_{0}$ reference Sherwood number, $0.023 R e^{0.8} S c^{0.4}$

$T$ temperature [K]

$U$ average velocity of air flow $[\mathrm{m} / \mathrm{s}]$

\section{Greek Symbols}

$\Delta t \quad$ duration of experiment [s]

$\Delta z \quad$ change of elevation at measurement point on naphthalene surface [m]
$\Lambda$ diffusion coefficient of naphthalene vapor in air $\left[\mathrm{m}^{2} / \mathrm{s}\right]$

$\mu \quad$ dynamic viscosity $\left[\mathrm{N} \cdot \mathrm{s} / \mathrm{m}^{2}\right]$

$\Omega \quad$ rotational speed $[\mathrm{rad} / \mathrm{s}]$

$\rho_{\mathrm{b}} \quad$ bulk density of naphthalene in air stream, $C_{m} / \dot{Q}\left[\mathrm{~kg} / \mathrm{m}^{3}\right]$

$\rho_{\mathrm{s}} \quad$ density of solid naphthalene $\left[\mathrm{kg} / \mathrm{m}^{3}\right]$

$\rho_{\mathrm{w}} \quad$ vapor density of naphthalene at wall $\left[\mathrm{kg} / \mathrm{m}^{3}\right]$

\section{Acknowledgments}

This study was sponsored in part by NASA Lewis Research Center, Cleveland, Ohio (Grant Number: NAS3-27739) and the Center for Energy and Mineral Resources, College Station, Texas.

\section{References}

Ambrose, D., Lawrenson, I.J. and Sparke, C.H.S., 1975. The vapor pressure of naphthalene, J. Chem. Thermodynamics, 7, 1173.

Clifford, R.J., Morris, W.D., Harasgama, S.P., 1984. An experimental study of local and mean heat transfer in a triangular-sectioned duct rotating in the orthogonal mode, Journal of Engineering for Gas Turbines and Power, 106, $661-667$.

Coleman, H.W. and Steele, W.G., 1989. Experimentation and Uncertainty Analysis for Engineers, John Wiley \& Sons, New York.

Dutta, S., Andrews, M.J. and Han, J.C., 1994. Numerical prediction of turbulent heat transfer in a rotating square duct with variable rotational buoyancy effects, HTD, 271, 161170.

Dutta, S., Han, J.C. and Lee, C.P., 1994. Effect of model orientation on local heat transfer in a rotating two-pass smooth triangular duct, HTD, 300, 147-153.

Ekkad, S.V. and Han, J.C., 1995. Local heat transfer distributions near a sharp $180^{\circ}$ turn of a two-pass smooth square channel using a transient liquid crystal image technique, Journal of Flow Visualization and Image Processing, 2, 285-297.

Hajek, T.J., Wagner, J.H., Johnson, B.V., Higgens, A.W. and Steuber, G.D., 1991. Effects of Rotations on Coolant Passage Heat Transfer: Volume I - Coolant Passages with Smooth Walls, NASA CR 4396, Vol. I.

Han, J.C. and Zhang, Y.M., 1992. Effect of uneven wall temperature on local heat transfer in a rotating square channel with smooth walls and radial outward flow, Journal of Heat Transfer, 114, 850-858.

Han, J.C., Zhang, Y.M. and Kalkuehler, K., 1993. Uneven wall temperature effect on local heat transfer in a rotating twopass square channel with smooth walls, Journal of Heat Transfer, 115, 912-920.

Han, J.C., Zhang, Y.M. and Lee, C.P., 1994. Influence of surface heating condition on local heat transfer in a rotating square channel with smooth walls and radial outward flow, Journal of Turbomachinery, 116, 149-158. 
Harasgama, S.P. and Morris, W.D., 1988. The influence of rotation on the heat transfer characteristics of circular, triangular, and square-sectioned coolant passage of gas turbine rotor blade, Journal of Turbomachinery, 110, 44-50.

Hwang, G.J. and Kuo, C.R., 1994. Experimental study of convective heat transfer in a rotating smooth serpentine passage with radial flow, $H T D, 300,139-146$.

Kuo, C.R. and Hwang, G.J., 1996. Experimental studies and correlations of radially outward and inward air-flow heat transfer in a rotating square duct, Journal of Heat Transfer, 118, 23-30.

McGrath, D.B. and Tse, D.G.N., 1995. A combined experimental/computational study of flow in turbine blade passage: Part II - Computational investigation, ASME Paper 95-GT149.

Mochizuki, S., Takamura, J., Yamawaki, S. and Yang, W.-J., 1994. Heat transfer in serpentine passages with rotation, Journal of Turbomachinery, 116, 133-140.

Mori, Y., Fukada, T. and Nakayama, M., 1971. Convective heat transfer in a rotating radial circular pipe (2nd Report), International Journal of Heat and Mass Transfer, 14, 1807-1824.

Mori, Y. and Nakayama, M., 1968. Convective heat transfer in rotating radial circular pipes (1st Report, Laminar Region), International Journal of Heat and Mass Transfer, 11, 1027-1040.

Morris, W.D. and Ayhan, T., 1979. Observations on the influence of rotation on heat transfer in the coolant channels of gas turbine rotor blades, Proc. Inst. Mech. Eng., 193, 303 311

Prakash, C. and Zerkle, R., 1992. Prediction of turbulent flow and heat transfer in a radially rotating square duct, Journal of Turbomachinery, 114, 835-846.

Rhie, C.M., 1986. A pressure based Navier-Stokes solver using the multigrid method, AIAA Paper 86-0207.

Soong, C.Y., Lin, S.T. and Hwang, G.J., 1991. An experimental study of convective heat transfer in radially rotating rectangular ducts, Journal of Heat Transfer, 113, 604-611.

Tse, D.G.N., Kreskovsky, J.P., Shamroth, S.J. and McGrath, D.B., 1994. A combined experimental/computational study of flow in turbine blade passage, NASA CR 4584.

Tse, D.G.N. and McGrath, D.B., 1995. A combined experimental/computational study of flow in turbine blade passage: Part I - Experimental study, ASME Paper 95-GT-355.

Wagner, J.H., Johnson, B.V. and Hajek, T.J., 1991a. Heat transfer in rotating passages with smooth and radial outwards flow, Journal of Turbomachinery, 113, 42-51.

Wagner, J.H., Johnson, B.V. and Kopper, F.C., 1991b. Heat transfer in rotating serpentine passages with smooth walls, Journal of Turbomachinery, 113, 321-330.

Yang, W.-J., Zhang, N. and Chiou, J., 1992. Local heat transfer in a rotating serpentine flow passage, Journal of Heat Transfer, 114, $354-361$ 


\section{ait \\ ENERGY MATERIALS}

M A N E Y publishing

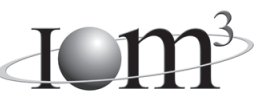

\section{Materials Science \& Engineering for Energy Systems}

Maney Publishing on behalf of the Institute of Materials, Minerals and Mining

The Institute of Materials, Minerals \& Mining

Economic and environmental factors are creating ever greater pressures for the efficient generation, transmission and use of energy. Materials developments are crucial to progress in all these areas: to innovation in design; to extending lifetime and maintenance intervals; and to successful operation in more demanding environments. Drawing together the broad community with interests in these areas, Energy Materials addresses materials needs in future energy generation, transmission, utilisation, conservation and storage. The journal covers thermal generation and gas turbines; renewable power (wind, wave, tidal, hydro, solar and geothermal); fuel cells (low and high temperature); materials issues relevant to biomass and biotechnology; nuclear power generation (fission and fusion); hydrogen generation and storage in the context of the 'hydrogen economy'; and the transmission and storage of the energy produced.

As well as publishing high-quality peer-reviewed research, Energy Materials promotes discussion of issues common to all sectors, through commissioned reviews and commentaries. The journal includes coverage of energy economics and policy, and broader social issues, since the political and legislative context influence research and investment decisions.

\section{CALL FOR PAPERS}

Contributions to the journal should be submitted online at http://ema.edmgr.com

To view the Notes for Contributors please visit: www.maney.co.uk/journals/notes/ema

Upon publication in 2006, this journal will be available via the Ingenta Connect journals service. To view free sample content online visit: www.ingentaconnect.com/content/maney

For further information please contact:

Maney Publishing UK

Tel: +44 (0)113 2497481 Fax: +44 (0)1132486983 Email: subscriptions@maney.co.uk

or

Maney Publishing North America

Tel (toll free): 8662975154 Fax: 6173546875 Email: maney@maneyusa.com

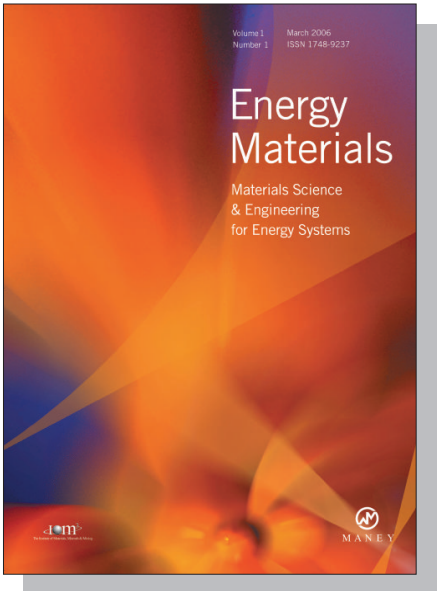

EDITORS

Dr Fujio Abe

NIMS, Japan

Dr John Hald, IPL-MPT, Technical University of Denmark, Denmark

Dr R Viswanathan, EPRI, USA

\section{SUBSCRIPTION INFORMATION}

Volume 1 (2006), 4 issues per year

Print ISSN: 1748-9237 Online ISSN: 1748-9245

Individual rate: $£ 76.00 / U S \$ 141.00$

Institutional rate: $£ 235.00 /$ US $\$ 435.00$

Online-only institutional rate: $£ 199.00 / U S \$ 367.00$

For special $\mathrm{IOM}^{3}$ member rates please email

subscriptions@maney.co.uk

\section{For further information or to subscribe online please visit www.maney.co.uk}



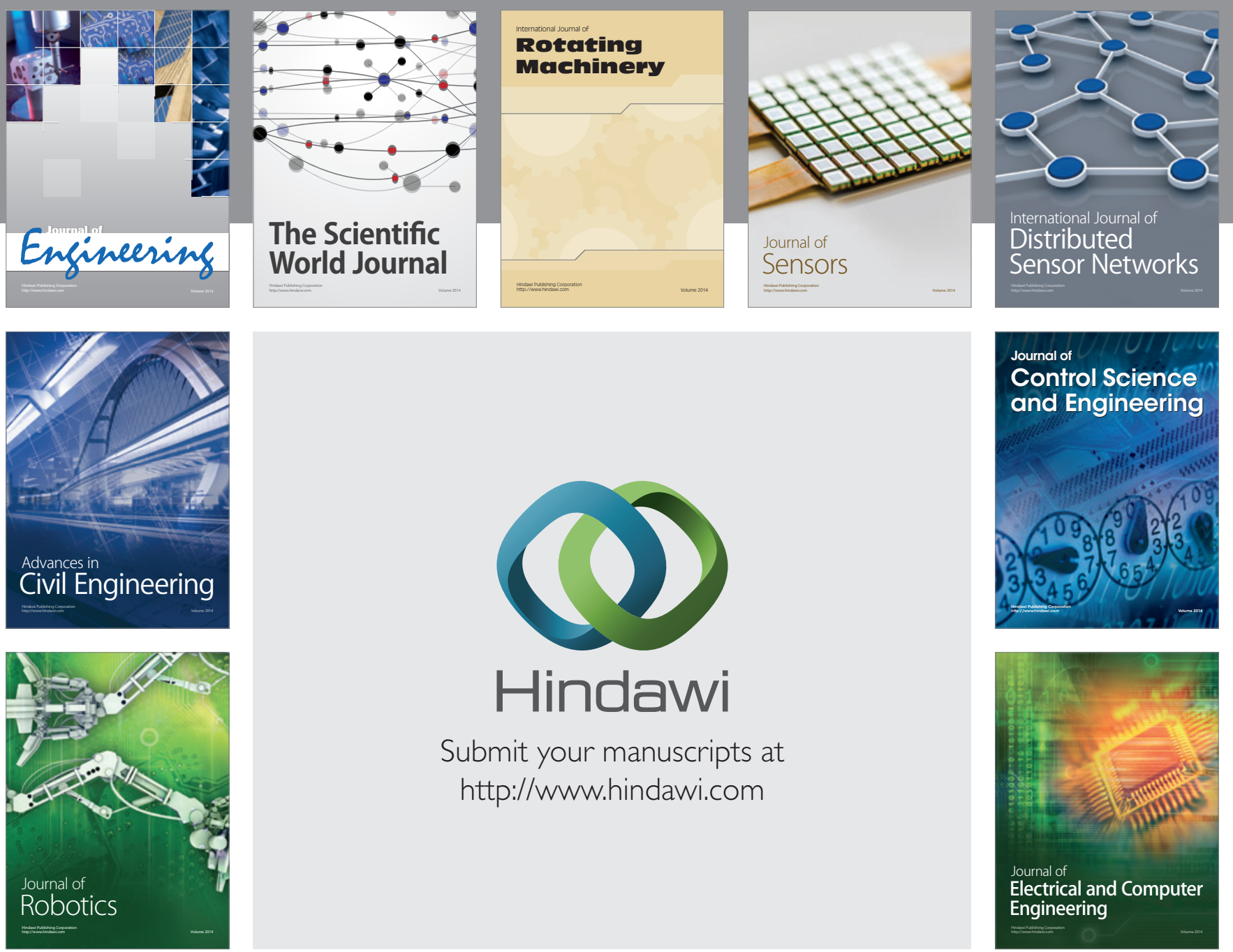

Submit your manuscripts at

http://www.hindawi.com
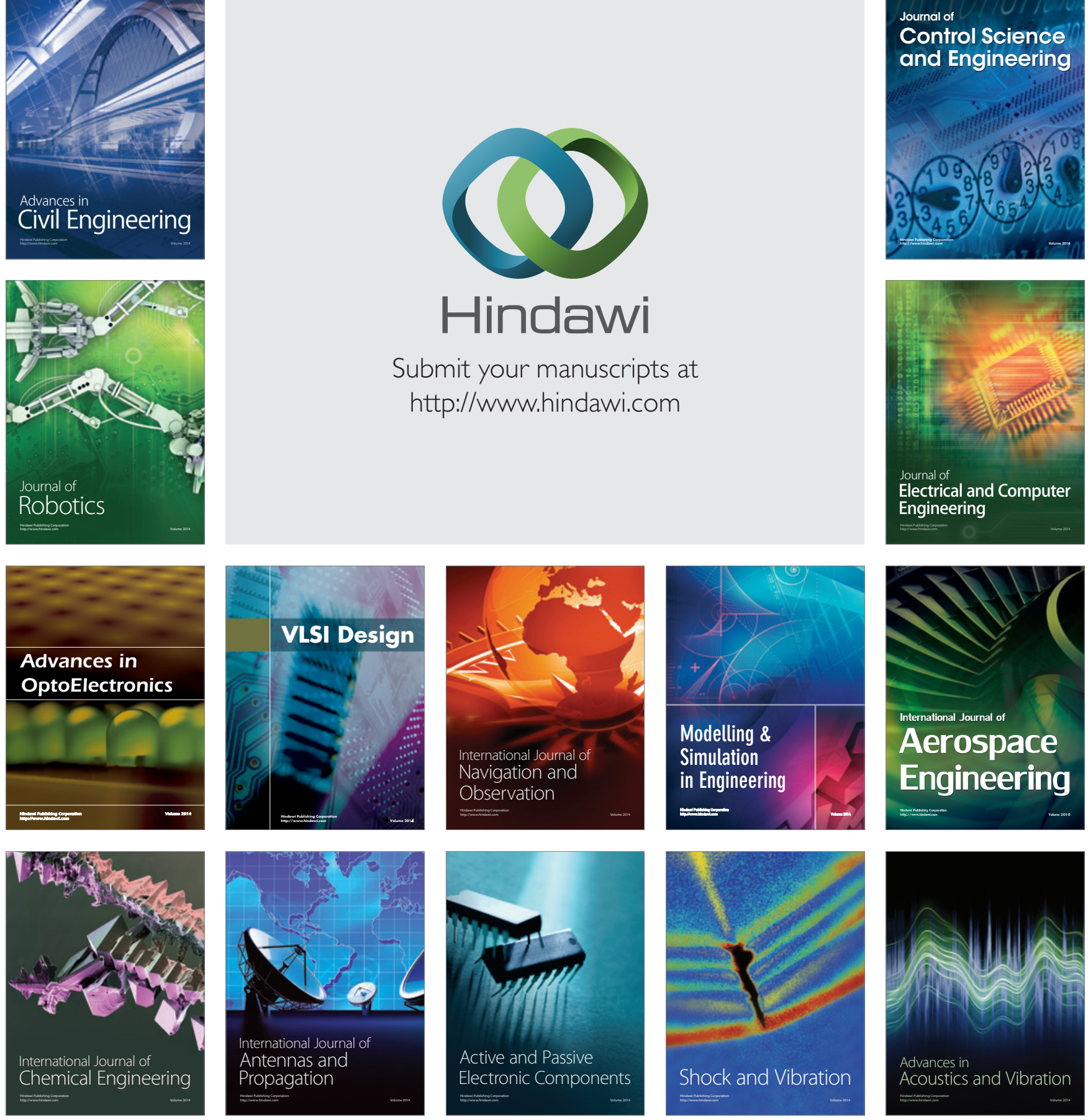